\title{
Clinical outcomes of early gastric cardiac cancer treated with endoscopic submucosal dissection in patients with different indications
}

\author{
Ting Fan ${ }^{1 \dagger}$, Qi Sun ${ }^{2 \dagger}$, Shouli Cao ${ }^{3 \dagger}$, Xiangshan Fan², Qin Huang ${ }^{2,4}$, Shu Zhang ${ }^{3}$, Ying Lv ${ }^{3}$, Xiaogi Zhang ${ }^{3}$, \\ Tingsheng Ling ${ }^{3}$, Lei Wang ${ }^{3^{*}}$, Xiaoping Zou ${ }^{3^{*}}$ and Guifang $\mathrm{Xu}^{3^{*}}$ (D)
}

\begin{abstract}
Background: Endoscopic submucosal dissection (ESD) has been accepted as a standard treatment for early gastric cardiac cancer (EGCC). Here, we investigate the clinical outcomes of the EGCC patients who underwent ESD in different indications.

Methods: From January 2011 to October 2019, we enrolled 502 EGCC lesions from 495 patients which were resected by ESD at our center. We retrospectively analyzed the short-term and long-term clinical outcomes among different indication groups.

Results: The number of the patients in the absolute indication (AI), expanded indication (EI) and beyond the expanded indication (BEI) groups was 265, 137 and 93, respectively. The en bloc resection rate was 100\%, 100\% and 98.9\% ( $P=0.185)$. The complete resection rate was $99.3 \%, 98.5 \%$ and $74.5 \%$, respectively $(P<0.001)$. During a median follow-up of 48.1 months, the lymph node metastasis rate was $0 \%, 0 \%$ and $2.3 \%(P<0.001)$. The distant metastasis rate was $0.4 \%, 0 \%$ and $2.3 \%(P=0.150)$. The five-year disease-specific survival rate in the $\mathrm{BEl}$ group was $96.6 \%(P=0.016)$, compared to $99.6 \%$ in the Al group and $100 \%$ in the El group.

Conclusion: The efficacy for ESD patients in El group was almost equal to the Al group. Patients in the BEl group showed generally favorable clinical outcomes and needed to be carefully checked after ESD. ESD may be an optional treatment for patients unsuitable for gastrectomy.
\end{abstract}

Keywords: Early gastric cardiac cancer, Endoscopic submucosal dissection, Treatment outcome, Beyond the expanded indication

\section{Background}

Gastric cardiac cancer locates in the gastric cardia beneath the gastroesophageal junction [1]. It may cross the gastroesophageal junction to invade the distal esophagus. Our previous study showed $23.3 \%$ of early

*Correspondence: 867152094@qq.com; wangl28zb@gmail.com; 13770771661@163.com; xuguifang@njglyy.com

${ }^{\dagger}$ Ting Fan, Qi Sun and Shouli Cao have contributed equally to this work

${ }^{3}$ Department of Gastroenterology, Nanjing Drum Tower Hospital, The

Affiliated Hospital of Nanjing University Medical School, Nanjing, China

Full list of author information is available at the end of the article gastric cancer (EGC) was gastric cardiac carcinoma in China [2], which is much higher compared to $7.0 \%$ in Japan [3] and $11.9 \%$ in western cohort [4]. The incidence of gastric cardiac cancer is rising worldwide for unknown reasons. Gastric cancer is the second most common cause of cancer-related death worldwide [5]. The five-year survival rate was less than $10 \%$ in the advanced stage [6]. As a result, it is urgent to perform early detection of gastric cancer through early screening [7]. Endoscopic resection should be applied for EGC [8]. Endoscopic mucosal resection (EMR) and 
endoscopic submucosal dissection (ESD) exhibited terrific clinical effects in the aspects of complete resection rate and survival outcomes if only the EGC lesions fit the standard and expanded indications [9]. Only a few studies have been published on the exact prevalence of early gastric cardiac cancer (EGCC) due to the rarity and a lack of widely accepted definition for gastric cardiac caner. According to our team's previous research, compared to distal gastric cancer, early proximal gastric cancers feature smaller size, deeper invasion [1]. Besides, EGCC had a significantly lower risk than non-EGCC, therefore, EGCC may be more suitable for endoscopic resection $[1,2,10,11]$. Our team have found based on the independent risk factors for gastric cardiac cancer in Chinese patients differ from those of distal gastric cancer or esophageal adenocarcinoma, the classification of gastric cardiac cancer should be considered as a separate gastric cancer entity in the Chinese population [12]. As a consequence, we wonder whether EGCC could achieve a favorable clinical outcome compared to the total EGC. It is widely accepted the EGCC patients of the AI and EI group can obtain excellent treatment outcome. However, a part of specimen is confirmed with lymphovascular invasion, massive submucosal invasion, undifferentiated histology or ulceration after ESD, which lead to "beyond the expanded indication" (BEI).

Until now, the long-term clinical consequence of the BEI group in EGCC patients has not been confirmed. We hope to evaluate the short-term and long-term treatment outcome in all EGCC patients, including the clinical application of the BEI patients.

\section{Methods}

\section{Patients}

From January 2011 to October 2019, 570 patients who underwent endoscopic resection for EGCC at the Affiliated Nanjing Drum Tower Hospital of Nanjing University Medical School were retrospectively enrolled consecutively. EGCC is defined as early cancers with epicenters located in a narrow region of about $3 \mathrm{~cm}$ below the esophagogastric junction (EGJ) [13]. EGJ is defined as the distally esophageal palisading vessels. Even if the EGJ was involved, it would be staged using the stomach cancer TNM and stage groups [14]. The exclusion criteria for entry into this study were: (1) low grade epithelial neoplasia $(n=25)$; (2) other type of carcinoma $(n=10)$; (3) no carcinoma $(n=28)$; (4) multiple lesions in different indications $(\mathrm{n}=4)$; (5) insufficient data $(\mathrm{n}=8) .495$ patients with 502 lesions were enrolled at last. A detailed flow chart on patient selection was exhibited in Additional file 1: Figure 1.

\section{Endoscopic resection}

Each patient underwent a routine gastroscopy to evaluate the status of margin and invasion depth of the EGCC lesion. Abdominal enhanced CT and endoscopic ultrasonography (EUS) were used to determine pretreatment tumor staging. All patients were intravenously anesthetized with midazolam and propofol before endoscopic resection. The ESD procedure was performed by 5 experienced endoscopists at our center with a standard procedure. The standard procedure is as follows: demarcation by indigo-carmine chromoendoscopy and NBI magnifying endoscopy; marking around the lesion; a circular mucosal incision around the marking spots and submucosal resection using a Dual knife step by step. Freshly endoscopically excised specimens were nailed on a dental wax plate, pictured, routinely measured, fixed overnight in $10 \%$ neutral formalin buffer then. Next, the specimens were cut evenly into 2-mm intervals. Size of the lesions, depth of tumor invasion, tumor differentiation, lymphovascular invasion and ESD resection margin were examined (Additional file 1: Figure 2).

\section{Definition}

EGCC patients were divided into absolute, expanded, beyond the expanded indication group according to the classification of the Japanese Gastric Cancer Association [9]. Absolute indication was defined as differentiated mucosal cancer smaller than $2 \mathrm{~cm}$ in diameter without ulcer. Expanded indications cover one of the circumstances: (1). Differentiated mucosal adenocarcinoma larger than $2 \mathrm{~cm}$ without ulceration or lymphovascular invasion; (2). Differentiated ulcer-positive mucosal cancer smaller than $3 \mathrm{~cm}$ in size without lymphovascular invasion; (3). Poorly differentiated or undifferentiated ulcernegative mucosal tumor less than $2 \mathrm{~cm}$ in size without lymphovascular invasion; (4). Differentiated ulcer-negative cancer with submucosal invasion less than $500 \mu \mathrm{m}$ in depth smaller than $3 \mathrm{~cm}$ without lymphovascular invasion. When it does not meet absolute and expand criteria, it is considered to be beyond the expanded indication [8].

En bloc resection referred to continuous monolithic resection after endoscopic resection. Complete resection was defined as endoscopic en bloc resection without histopathological evidence of tumor involvement of margins. Curative resection referred to en bloc resection, tumor size less than $2 \mathrm{~cm}$, histologically of differentiated type, pT1a, no residual tumor at the margin and no lymphovascular invasion. For lesions under expanded indication, the resection is considered as curative when all of the following condition are fulfilled: en bloc resection, 
negative horizontal and vertical margin and no lymphovascular infiltration [8].

The ESD-related complications included significant bleeding, perforation, and stenosis. Significant bleeding was a drop of over $2 \mathrm{~g} / \mathrm{dL}$ hemoglobin or clinical features instance of endoscopic visible melena or hematemesis. According to whether significant bleeding occurred over $48 \mathrm{~h}$ after ESD, we divided it into early and late delayed bleeding [15]. When we observed a hole in the stomach wall under endoscope or a chest X-ray that found free air of the abdomen, it could be diagnosed as a perforation. When the endoscope couldn't reach the cardiac through distal esophagus because of the excessive contraction of the cardiac, we considered that a stenosis had occurred [16].

Local recurrence was diagnosed once a new tumor was discovered at the prior ESD site. Tumors that were detected at other sites within 1 year after the ESD were interpreted as synchronous tumors, while tumors that were revealed at other sites more than 1 year after the ESD procedure were termed metachronous tumors.

\section{eCura system}

We evaluated the lymph node metastasis rate of EGCC patients after ESD by eCura system. The eCura system consists of five clinicopathological factors, which are scored as followed: 1 point each for tumor size $>30 \mathrm{~mm}$, positive vertical margin, venous invasion, and submucosal invasion over $500 \mu \mathrm{m}$ and three points for lymphatic invasion. And the patients are divided into three groups according the total points: low risk ( $0-1$ points), intermediate risk ( $2-4$ points) and high risk (5-7 points) [17]. In this study, we used the eCura system to access the disease specific survival and cancer recurrence rate between the two BEI patients with or without additional surgery.

\section{Follow-up}

Patients were required scheduled endoscopy examination in the first 3, 6, 12 months after ESD procedure, and once a year thereafter. The surveillance of thoracic and abdominal CT was performed after 6,12 months. When endoscopists found a new tumor at a previous ESD location, local recurrence was considered to occur. Synchronized tumors were diagnosed once tumors were found at other sites within a year of ESD, and metachronous tumors were that occurred at the other sites over a year after ESD.

\section{Statistical analysis}

Statistics was analyzed by SPSS 23.0 (IBM, Armonk, New York, USA). Student's tor Chi-square test was applied to assess the differences between measurement data.
Chi-square test or Fisher's exact test was called for the analyses of categorical variables to obtain statistical significance. Kaplan-Meier method was used to estimate the survival rates. A $P$ value of $<0.05$ was regarded as statistically significant.

\section{Results \\ Baseline demographic and clinical features}

A total of 570 patients had undergone ESD and 495 patients with 502 lesions were enrolled with the following criteria, among whom 265 patients with 271 lesions were enrolled in the AI group, 137 patients with 137 lesions in the EI group and 93 patients with 94 lesions in the BEI group. 5 patients were withdrawn during the follow-up. 450 patients were enrolled for the long-term outcome analysis in the end (Additional file 1: Figure 3).

As shown in Table 1, the average age was 65.5 (range 44-87) and $82 \%$ were male. 291 patients (58.8\%) had a smoking history, 263 patients (53.1\%) had a drinking habit and 230 patients (46.5\%) regularly ate pickled food. Nearly half of the patients $(40.8 \%)$ had a family tumor history. The most common complication was hypertension $(32.7 \%, 162 / 495) .14$ patients $(2.8 \%)$ suffered from gastroesophageal reflux disease.

\section{Endoscopic and pathological characteristics}

The average tumor size was $12 \mathrm{~mm}$ (range 2-20) in the AI group, $23 \mathrm{~mm}$ (range 6-66) in the EI group, and $27 \mathrm{~mm}$ (range $5-65)$ in the BEI group $(P<0.001)$ (Table 2). Most lesions were smaller than $20 \mathrm{~mm}(73.7 \%$, 370/502). The most common site of EGCC was posterior curvature $(51.0 \%, 256 / 502)$, followed by lesser curvature $(42.2 \%, 212 / 502)$. The most common endoscopic infiltration growth pattern was INFa $(66.3 \%, 333 / 502)$. The most common macroscopic pattern, in the descending order, was 0-IIc $(45.2 \%, 227 / 502)$, 0-IIa + IIc $(27.9 \%, 140 / 502)$, 0-IIa $(14.9 \%, 75 / 502), 0$-IIb $(10.0 \%, 50 / 502), 0$-III (1.2\%, $6 / 502)$, and $0-\mathrm{I}(0.8 \%, 4 / 502)$. All tumor lesions in the AI group were intramucosal and differentiated. Instead, in the BEI group, 5 patients $(5.3 \%, 5 / 94)$ had undifferentiated carcinoma and the majority $(94.6 \%, 89 / 94)$ had submucosal invasion $(P<0.001) .24$ patients $(4.8 \%, 24 / 502)$ had ulceration over the three group and 13 patients $(13.8 \%, 13 / 94)$ in the BEI group were positive. Focal distal esophageal involvement was detected in $12.0 \%(60 / 502)$ in all patients. Lymphovascular invasion was identified in $3.0 \%(15 / 502)$ in all patients. Gastritis cystica profunda was found in over $24 \%$ of lesions (122/502) and there were no differences among the three groups. Overall positive rate of helicobacter pylori was $56.8 \%$ and the difference among the three groups was non-significant. Atrophic gastric carditis was found in 89.4\% (449/502). 
Table 1 Demographic and clinical features characteristics of early gastric cardiac cancer

\begin{tabular}{|c|c|c|c|c|c|}
\hline Characters & Total $(n=495)$ & $\begin{array}{l}\text { Absolute indication } \\
(n=265)\end{array}$ & $\begin{array}{l}\text { Expanded indication } \\
(n=137)\end{array}$ & $\begin{array}{l}\text { Beyond expanded } \\
\text { indication }(n=93)\end{array}$ & $P$ value \\
\hline Gender, number (\%) & & & & & 0.093 \\
\hline Male & $406(82.0)$ & $214(80.8)$ & $120(87.6)$ & $72(77.4)$ & \\
\hline Female & $89(18.0)$ & $51(19.2)$ & $17(12.4)$ & $21(22.6)$ & \\
\hline Age (year) & $65.5(44-87)$ & $65.1(45-85)$ & $65.4(45-79)$ & $67.2(44-87)$ & 0.059 \\
\hline Smoke, number (\%) & $291(58.8)$ & $152(57.4)$ & $89(65.0)$ & $50(53.8)$ & 0.187 \\
\hline Drink, number (\%) & $263(53.1)$ & $137(51.7)$ & $79(57.7)$ & $47(50.5)$ & 0.449 \\
\hline Pickled food, number (\%) & $230(46.5)$ & $113(42.6)$ & $74(54.0)$ & $43(46.2)$ & 0.095 \\
\hline $\mathrm{BMI}\left(\mathrm{kg} / \mathrm{m}^{2}\right)(\mathrm{SD})$ & $23.0(3.2)$ & $23.1(3.4)$ & $22.9(3.1)$ & $23.2(3.0)$ & 0.851 \\
\hline Family history, number (\%) & $202(40.8)$ & $93(35.1)$ & $63(46.0)$ & $46(49.5)$ & 0.018 \\
\hline Complications, number (\%) & & & & & 0.767 \\
\hline Diabetes mellitus & $36(7.3)$ & $14(5.3)$ & $13(9.5)$ & $9(9.7)$ & \\
\hline Hypertension & $162(32.7)$ & 89 (33.6) & $40(29.2)$ & $33(35.5)$ & \\
\hline Hyperlipidemia & $9(1.8)$ & $6(2.3)$ & $1(0.7)$ & $2(2.2)$ & \\
\hline Cardiovascular disease & $20(4.0)$ & $12(4.5)$ & $4(2.9)$ & $4(4.3)$ & \\
\hline Hepatitis B & $25(5.1)$ & $14(5.3)$ & $8(5.8)$ & $3(3.2)$ & \\
\hline Chromic pulmonary disease & $32(6.5)$ & $17(6.4)$ & $10(7.3)$ & $5(5.4)$ & \\
\hline Reflux esophagitis & $14(2.8)$ & $6(2.3)$ & $3(2.2)$ & $5(5.4)$ & \\
\hline
\end{tabular}

\section{Short-term outcomes and complications based on indication}

As Table 3 clarified, the overall en bloc resection rate was 99.8\% (501/502), among which only one lesion in the BEI group was broken. Complete resection rate of all cases was 94.4\% (474/502); 99.3\% (269/271), 98.5\% (135/137) and $74.5 \%(70 / 94)$, respectively $(P<0.001)$. The rate of curative resection was $79.9 \%$ in all the patients: $98.5 \%$ (267/271), 97.8\% (134/137) and 0\% (0/94), respectively $(P<0.001)$. Factors associated non-curative resection included lymphovascular infiltration $(n=15)$, submucosal invasion $(n=71)$, positive vertical margin $(n=4)$, positive lateral margin $(n=21)$, or positive lateral and vertical margin $(n=3)$.

In the aspect of complications, 12 cases had significant bleeding, in which 8 cases were early delayed bleeding, 4 cases were late delayed bleeding. The early delayed bleeding rate was $0.4 \%(1 / 271), 1.5 \%(2 / 137), 5.3 \%(5 / 94)$ in the $\mathrm{AI}, \mathrm{EI}$ and BEI group, respectively, which was a difference of statistics among the three groups $(P=0.004)$. This could be due to the larger size of tumor lesions and submucosal invasion. Luckily, all the patients who suffered from bleeding were successfully managed by endoscopic hemostasis $(n=11)$ and the use of hemostatic drugs such as octreotide acetate and somatostatin $(n=1)$. Perforation was found in $1 \mathrm{AI}$ patient and this patient's symptoms improved after conservative treatment. Stenosis was a common complication of patients who underwent ESD and was found in $3.6 \%(18 / 502)$ patients, among whom 4 patients $(1.5 \%, 4 / 271)$ were in the AI group, 10 patients
(7.3\%, 10/137) belonged to the EI group and 4 patients $(4.4 \%, 4 / 94)$ were members of the BEI group $(P=0.002)$. After balloon dilation, the symptoms of stenosis were easily improved. The presence of stenosis was positively related to a circumferential extent of the mucosal defect of $>3 / 4$ or longitudinal extent of $>5 \mathrm{~cm}$ in length according to the previous investigation [18]. The median time of ESD operations was 65.3 min (range 10-246), while the BEI patients required longer procedure time, which was $72.9 \mathrm{~min}$ (range $18-223)(P=0.007)$. The average hospitalization time was 6.6 days (range $2-19$ ). Similarly, the EI and BEI patients stayed longer than the AI patients $(P=0.012)$.

\section{Long-term therapeutic outcomes according to the indication}

During the median follow-up of 48.1 months (range 18-101), 45 patients $(9.1 \%, 45 / 495)$ were lost during follow-up. Additional surgery was carried out for 7 AI patients $(2.9 \%, 7 / 239), 10$ EI patients $(8.1 \%, 10 / 124)$ and 42 BEI patients $(48.3 \%, 42 / 87)$ (Table 4$)$. Local recurrence was found in only one AI patient because of the residual tumor $(P=1.000)$. Synchronous cancer was detected in 39 patients $(8.7 \%, 39 / 450)$, and there was no statistically significant difference among the three groups. The similar conclusion was achieved for metachronous cancer. During the follow-up, 2 BEI patients $(2.3 \%, 2 / 87)$ were found to have lymph node metastasis $(P=0.037)$. These patients underwent the additional surgery and survived well during long-term follow-up. Distant metastasis 
Table 2 Endoscopic and Pathological Characteristics of early gastric cardiac cancer

\begin{tabular}{|c|c|c|c|c|c|}
\hline Characters & Total $(n=502)$ & $\begin{array}{l}\text { Absolute } \\
\text { indication } \\
(n=271)\end{array}$ & $\begin{array}{l}\text { Expanded } \\
\text { indication }(n=137)\end{array}$ & $\begin{array}{l}\text { Beyond expanded } \\
\text { indication }(n=94)\end{array}$ & $p$ value \\
\hline Direction, number (\%) & & & & & 0.151 \\
\hline Anterior wall & $13(2.6)$ & $9(3.3)$ & $2(1.5)$ & $2(2.1)$ & \\
\hline Posterior wall & $256(51.0)$ & $147(54.2)$ & $68(49.6)$ & $41(43.6)$ & \\
\hline Lesser curvature & $212(42.2)$ & $100(36.9)$ & $64(46.7)$ & $48(51.1)$ & \\
\hline Greater curvature & $15(3.0)$ & $12(4.4)$ & $2(1.5)$ & $1(1.1)$ & \\
\hline Circumferential & $6(1.2)$ & $3(1.1)$ & $1(0.7)$ & $2(2.1)$ & \\
\hline Mean Tumor size (mm), number (\%) & & & & & $<0.001$ \\
\hline$\leq 20$ & $370(73.7)$ & $271(100)$ & $52(38.0)$ & $47(50.0)$ & \\
\hline $20-30$ & $87(17.3)$ & $0(0)$ & $67(48.9)$ & $20(21.3)$ & \\
\hline$>30$ & $45(9.0)$ & $0(0)$ & $18(13.1)$ & $27(28.7)$ & \\
\hline Invasion depth, number (\%) & & & & & $<0.001$ \\
\hline LPM & $168(33.5)$ & $137(50.6)$ & $29(21.2)$ & $2(2.1)$ & \\
\hline MM & $189(37.6)$ & $134(49.4)$ & $52(38.0)$ & $3(3.2)$ & \\
\hline SM1 & $74(14.7)$ & $0(0)$ & $56(40.9)$ & $18(19.1)$ & \\
\hline $\mathrm{SM} 2$ & $71(14.1)$ & $0(0)$ & $0(0)$ & $71(75.5)$ & \\
\hline Endoscopic infiltration (INF) model, number (\%) & & & & & $<0.001$ \\
\hline INFa & $333(66.3)$ & $198(73.1)$ & $88(64.2)$ & $47(50.0)$ & \\
\hline INFb & $143(28.5)$ & $64(23.6)$ & $44(32.1)$ & $35(37.2)$ & \\
\hline INFC & $26(5.2)$ & $9(3.3)$ & $5(3.6)$ & $12(12.8)$ & \\
\hline Macroscopic type, number (\%) & & & & & $<0.001$ \\
\hline $0-1$ & $4(0.8)$ & $3(1.1)$ & $0(0)$ & $1(1.1)$ & \\
\hline $0-\| A$ & $75(14.9)$ & $49(18.1)$ & $12(8.8)$ & $15(3.0)$ & \\
\hline $0-\| B$ & $50(10.0)$ & $32(11.8)$ & $16(11.7)$ & $1(1.1)$ & \\
\hline $0-\| C$ & $227(45.2)$ & $112(41.3)$ & $74(54.0)$ & $41(43.6)$ & \\
\hline $0-\|A+\| C$ & $140(27.9)$ & $75(27.7)$ & $32(23.4)$ & $33(35.1)$ & \\
\hline $0-111$ & $6(1.2)$ & $0(0)$ & $3(2.2)$ & $3(3.2)$ & \\
\hline Ulceration, number (\%) & & & & & $<0.001$ \\
\hline Presence & $24(4.8)$ & $0(0)$ & $11(8.0)$ & $13(13.8)$ & \\
\hline Absence & $478(95.2)$ & $271(0)$ & $126(92.0)$ & $81(86.2)$ & \\
\hline Pathological type, number (\%) & & & & & $<0.001$ \\
\hline WD & $279(55.6)$ & $179(66.1)$ & $78(56.9)$ & $22(23.4)$ & \\
\hline $\mathrm{MD}$ & $123(24.5)$ & $51(18.8)$ & $31(22.6)$ & $41(43.6)$ & \\
\hline$W D+M D$ & $92(18.3)$ & $41(15.1)$ & $25(18.2)$ & $26(27.7)$ & \\
\hline PD & $8(1.6)$ & $0(0)$ & $3(2.2)$ & $5(5.3)$ & \\
\hline Lymphatic and vascular invasion, number (\%) & & & & & $<0.001$ \\
\hline Presence & $15(3.0)$ & $0(0)$ & $1(0.7)$ & $14(14.9)$ & \\
\hline Absence & $487(97.0)$ & $271(100)$ & $136(99.3)$ & $80(85.1)$ & \\
\hline Esophagus involvement, number (\%) & & & & & $<0.001$ \\
\hline Presence & $60(12.0)$ & $25(9.2)$ & $12(8.8)$ & $23(24.5)$ & \\
\hline Absence & $462(88.0)$ & $246(90.8)$ & $125(91.2)$ & $71(75.5)$ & \\
\hline Gastritis cystica profunda, number (\%) & & & & & 0.062 \\
\hline Presence & $122(24.3)$ & $55(20.3)$ & $40(29.2)$ & $27(28.7)$ & \\
\hline Absence & $380(75.7)$ & $216(79.7)$ & $97(70.8)$ & $64(71.3)$ & \\
\hline HP infection, number (\%) & & & & & 0.256 \\
\hline Presence & $285(56.8)$ & $149(55.0)$ & $87(63.5)$ & $54(57.4)$ & \\
\hline Absence & $217(43.2)$ & $122(45.0)$ & $50(36.5)$ & $40(42.6)$ & \\
\hline Atrophic gastritis, number (\%) & & & & & 0.864 \\
\hline Presence & $449(89.4)$ & $243(89.7)$ & $121(88.3)$ & $85(90.4)$ & \\
\hline
\end{tabular}


Table 2 (continued)

\begin{tabular}{lcccc}
\hline Characters & Total $(\mathrm{n}=502)$ & $\begin{array}{l}\text { Absolute } \\
\text { indication } \\
(\mathrm{n}=271)\end{array}$ & $\begin{array}{l}\text { Expanded } \\
\text { indication }(\mathrm{n}=137)\end{array}$ & $\begin{array}{l}\text { Beyond expanded } \\
\text { indication }(\mathrm{n}=94)\end{array}$ \\
\hline Absence & $53(10.6)$ & $28(10.3)$ & $16(11.7)$ & $9(9.6)$ \\
\hline
\end{tabular}

Table 3 Short-term outcomes and complications based on indication

\begin{tabular}{|c|c|c|c|c|c|}
\hline Characters & Total $(n=502)$ & $\begin{array}{l}\text { Absolute indication } \\
(n=271)\end{array}$ & $\begin{array}{l}\text { Expanded indication } \\
(n=137)\end{array}$ & $\begin{array}{l}\text { Beyond Expanded } \\
\text { indication }(n=94)\end{array}$ & $p$ value \\
\hline En bloc resection, number (\%) & $501(99.8)$ & $271(100)$ & $137(100)$ & $93(98.9)$ & 0.185 \\
\hline Complete resection, number (\%) & $474(94.4)$ & $269(99.3)$ & $135(98.5)$ & $70(74.5)$ & $<0.001$ \\
\hline Curative resection, number (\%) & $401(79.9)$ & $267(98.5)$ & $134(97.8)$ & $0(0)$ & $<0.001$ \\
\hline Free vertical margin, number (\%) & 495 (98.6) & $271(100)$ & $136(99.3)$ & 88 (93.6) & $<0.001$ \\
\hline Free lateral margin, number (\%) & $478(95.2)$ & $269(99.3)$ & $135(98.5)$ & $74(78.7)$ & $<0.001$ \\
\hline \multicolumn{6}{|l|}{ Complication, number (\%) } \\
\hline Significant bleeding & $12(2.4)$ & $5(1.8)$ & $2(1.5)$ & $5(5.3)$ & 0.128 \\
\hline Early delayed & $8(1.6)$ & $1(0.4)$ & $2(1.5)$ & $5(5.3)$ & 0.004 \\
\hline Late delayed & $4(0.8)$ & $4(1.5)$ & $0(0)$ & $0(0)$ & 0.306 \\
\hline Perforation & $1(0.2)$ & $1(0.4)$ & $0(0)$ & $0(0)$ & 1 \\
\hline Stenosis & $18(3.6)$ & $4(1.5)$ & $10(7.3)$ & $4(4.3)$ & $<0.001$ \\
\hline Median procedure time (min) (range) & $65.3(10-353)$ & $59.9(10-353)$ & $70.8(18-223)$ & $72.9(10-246)$ & 0.007 \\
\hline Median hospital stays (day) (range) & $6.6(2-19)$ & $6.4(3-14)$ & $7.0(4-19)$ & $6.8(2-14)$ & 0.012 \\
\hline
\end{tabular}

Table 4 Long-term therapeutic outcomes according to EGCC subgroup

\begin{tabular}{|c|c|c|c|c|c|}
\hline Characters, n (\%) & Total $(n=450)$ & $\begin{array}{l}\text { Absolute indication } \\
(n=239)\end{array}$ & $\begin{array}{l}\text { Expanded indication } \\
(\mathrm{n}=124)\end{array}$ & $\begin{array}{l}\text { Beyond expanded } \\
\text { indication }(n=87)\end{array}$ & $p$ value \\
\hline Median time, months (SD) & $48.1(18.8)$ & $49.2(20.0)$ & $47.5(17.1)$ & $45.7(17.5)$ & 0.291 \\
\hline Local recurrence, number (\%) & $1(0.2)$ & $1(0.4)$ & $0(0)$ & $0(0)$ & 1.000 \\
\hline Synchronous cancer, number (\%) & $39(8.7)$ & $26(10.9)$ & $7(5.6)$ & $6(6.9)$ & 0.197 \\
\hline Metachronous cancer, number (\%) & $7(1.4)$ & $6(2.5)$ & $1(0.8)$ & $0(0)$ & 0.340 \\
\hline Additional surgery, number (\%) & $59(13.1)$ & $7(2.9)$ & $10(8.1)$ & $42(48.3)$ & $<0.001$ \\
\hline Observation, number (\%) & $391(86.9)$ & $232(97.1)$ & $114(91.9)$ & $45(51.7)$ & $<0.001$ \\
\hline Lymph node metastasis, number (\%) & $2(0.4)$ & $0(0)$ & $0(0)$ & $2(2.3)$ & 0.037 \\
\hline Distant metastasis, number (\%) & $3(0.7)$ & $1(0.4)$ & $0(0)$ & $2(2.3)$ & 0.150 \\
\hline Overall death, number (\%) & $17(3.8)$ & $8(3.3)$ & $3(2.4)$ & $6(6.9)$ & 0.212 \\
\hline Disease related death, number (\%) & $4(0.9)$ & $1(0.4)$ & $0(0)$ & $3(3.4)$ & 0.030 \\
\hline
\end{tabular}

was developed in one AI patient and two BEI patients (Table 4). They didn't receive the additional surgery and passes away unfortunately. Disease-specific death occurred in 4 patients $(0.9 \%, 4 / 450)$; $1(0.4 \%, 1 / 239)$ in the AI group, no patient in the EI group and $3(3.4 \%$, $3 / 87)$ in the BEI group $(P=0.030)$. The AI patient was dead because of metastasis whose lateral margin was positive and he refused the additional surgery. One BEI patient was dead due to the significant bleeding after the additional surgery. The other two patients passed away related to distant metastasis without additional surgery
(Table 5). Five-year overall survival rates were 96.1\% (AI), 98.3\% (EI) and 89.1\% (BEI), which didn't have any statistic difference $(P=0.180)$ (Fig. 1a). Five-year disease-specific survival rates of three groups were $99.6 \%, 100 \%$ and $96.6 \%$ in the AI, EI and BEI group, respectively, which was significantly different between each other $(P=0.016)$ (Fig. 1b). Besides, we analyzed whether the additional surgery was necessary for the patients in the BEI group. After ESD surgery, 93 patients were enrolled into the BEI group based on postoperative pathology. 6 patients were lost during the follow-up. 42 of the remaining $87 \mathrm{BEI}$ 


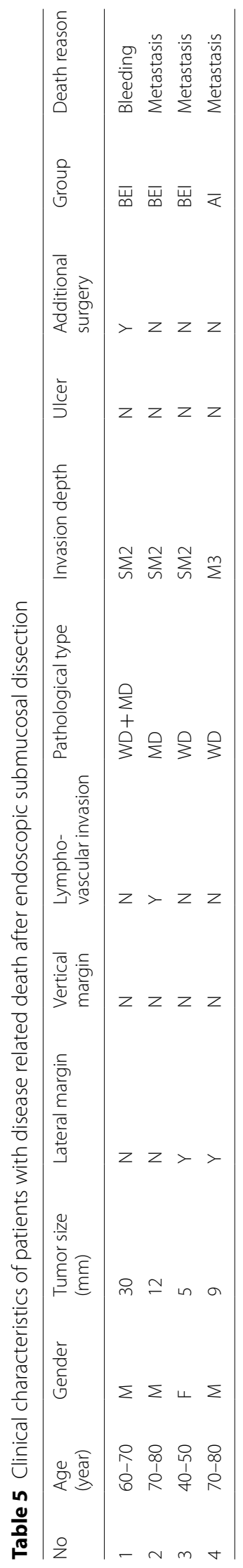



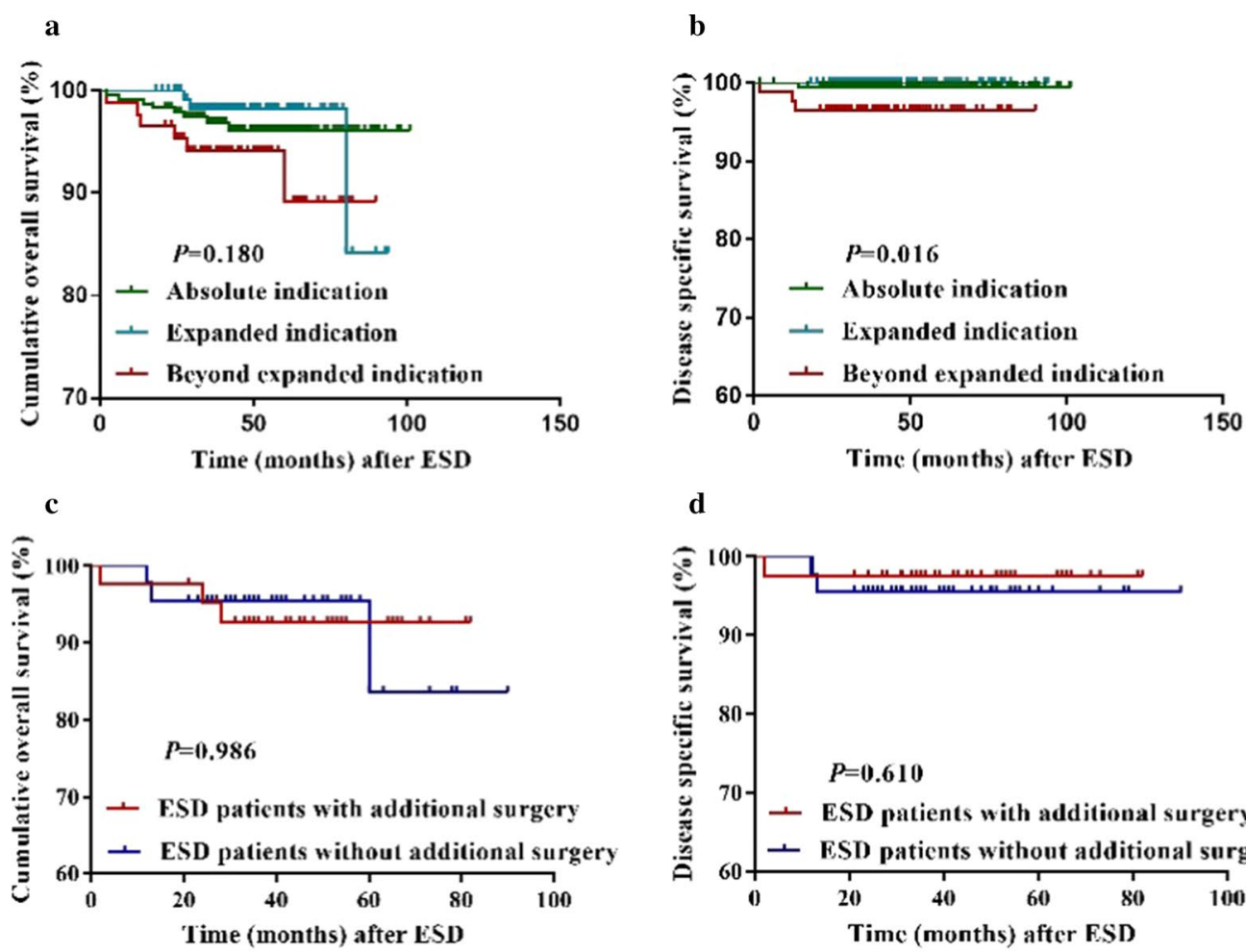

d
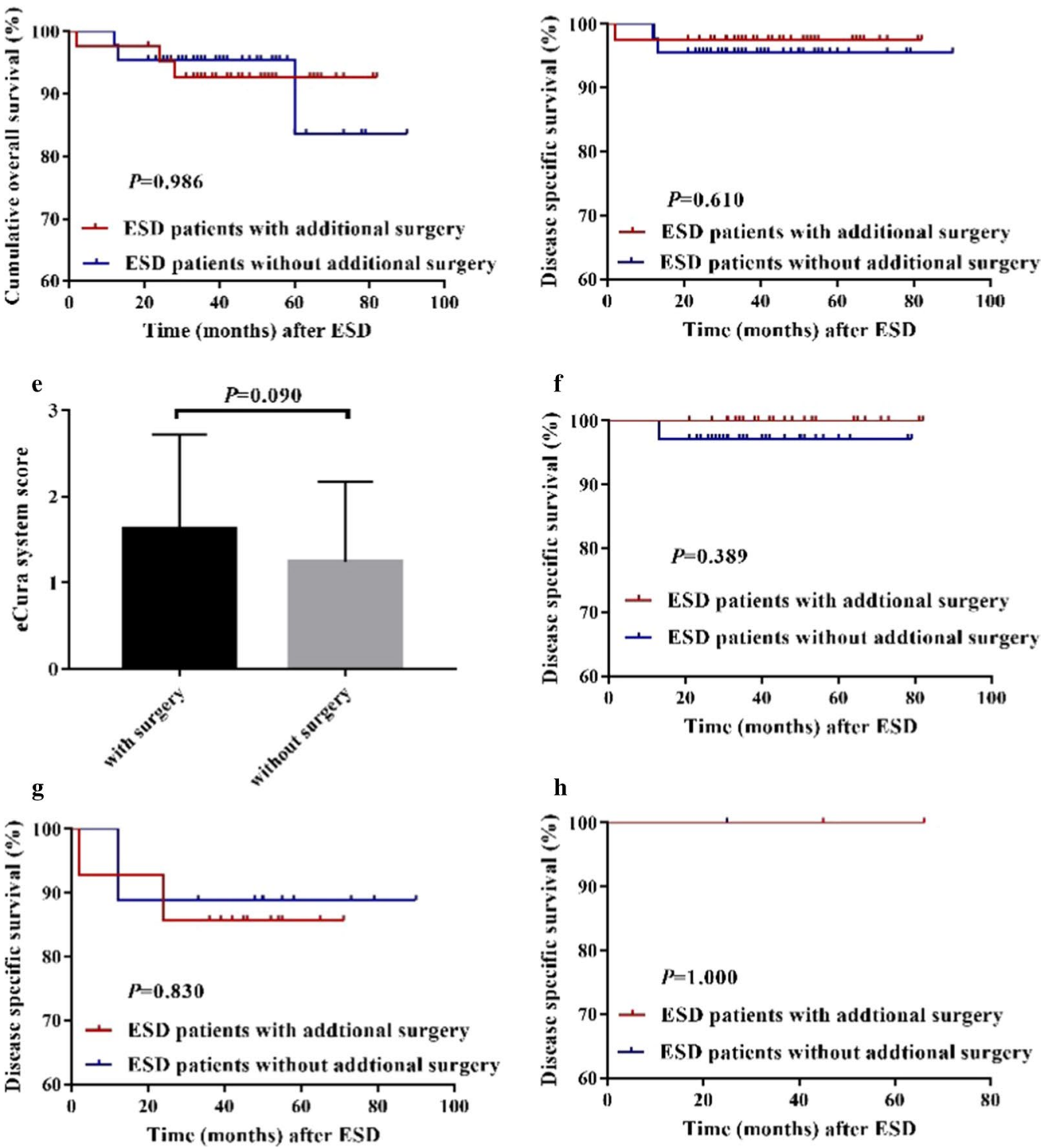

Fig.1 Kaplan-Meier plots of survival among patients after ESD. a Overall survival between three groups. $\mathbf{b}$ Disease specific survival between three groups. c Overall survival between BEl patients with or without additional surgery. $\mathbf{d}$ Disease specific survival between BEl patients with or without additional surgery. $\mathbf{e}$ The eCura system score of the BEl patients with or without additional surgery. $\mathbf{f}$ The disease specific survival of the BEI patients with or without additional surgery in low risk category. $\mathbf{g}$ The disease specific survival of the BEl patients with or without additional surgery in intermediate risk category. $\mathbf{h}$ The disease specific survival of the BEl patients with or without additional surgery in high risk category 
patients underwent additional surgery according to the doctor's advice. As we can see in Fig. 1c, d, the additional surgery didn't have an influence on neither the overall survival nor the disease specific survival.

We wondered why the disease specific survival was no significantly difference between the two BEI group with or without the additional surgery. So, we applied the eCura system to evaluate whether there was any difference between these two groups. According to the generally accepted method, we divided the BEI patients with or without additional surgery into three categories (Additional file 1: Table 1). The detailed scores had no difference between the two groups (Fig. 1e), which meant the LNM risk was resemble between the BEI patients with or without surgery, consistent with the survival analysis. In low risk category, disease specific survival was higher in the patient accepted the additional surgery $(100 \%$ vs $97.1 \%)$, but was no significant difference for the two groups ( $p=0.389$; Fig. 1f). In the intermediate risk category, one patient in each of the two groups had a diseaserelated death. We could achieve the similar conclusion: the patients received the additional surgery has higher five-year disease-free survival rate, but there was no significantly different $(92.9 \%$ vs $88.9 \%, p=0.830$; Fig. $1 \mathrm{~g}$ ). Since there was no disease-related death of the patients in the high-risk category and a small number of cases, we could not achieve a reliable survival analysis for the data (Fig. 1h). In summary, the patients in the BEI group may not benefit from the additional surgery after ESD in our research due to the small account of data.

\section{Discussion}

This is a large-scale research to compare the short- and long-term clinical outcomes among the absolute indication, expanded indication and beyond the expanded indication EGCC patients of endoscopic resection. Across hospitals all over the world, endoscopic resection has gain widely acceptation as a standard treatment of EGC under absolute and expanded criteria as an alternative to surgical resection of distal esophagus and proximal stomach [19-23]. ESD has advantages in lower rates of acute complications and comparable overall survival [22]. Several studies have displayed the effectiveness and safety of endoscopic resection for adenocarcinoma of EGJ [24, 25]. For the cancer located in EGJ, it encompasses both gastric cardia adenocarcinoma (GEA) and Barrett's esophageal adenocarcinoma (BEA) due to short-segment Barrett's esophagus. Few researches have specially focused on the clinical outcome of ESD for these gastric cardiac adenocarcinomas. Osumi et al. reported curative resection rate was higher in GCA group (81\%) than BEA group (60\%) [26]. Jang et al. enrolled 82 patients with gastric cardiac tumors and the en bloc resection, complete resection, and curative resection rates were $87 \%, 79 \%$, and $66 \%$ [27]. A handful of researches have proved ESD is an efficient way to cure EGCC patients. Due to the small sample size, more persuasive studies needed to be conducted.

In our study, we enrolled 495 patients with 502 ESDrelated EGCC lesions. The effectiveness of ESD was confirmed by comparing the short and long-term clinical consequence among the AI, EI and BEI groups. No significant difference was found in demographic statistics for these three groups. In the present study, patients in BEI group had more family history than $\mathrm{AI}$ and EI groups $(P=0.018)$. Increased tumor size, deeper tumor invasion, presence of ulcer and poor differentiated were significantly different among the three groups, which was consistent with the definition. In our research, atrophy of the mucosa around the tumor lesion could be found in the vast majority EGCC patients. Atrophic gastritis and intestinal metaplasia were the most significant risk factors for gastric cancer $[28,29]$, thus the endoscopic surveillance in these high risk patients were expected to be extremely important.

The complete resection and curative resection rates in the AI group were meaningfully higher in comparison with the other two groups $(P<0.001)$. This was closely related to the positive vertical and lateral cutting margins in the EI and BEI groups. Suzuki et al. drew the conclusion through their research that positive margins with submucosal infiltration (odds ratio 3.6) and lymphovascular invasion (odds ratio 3.5) had significant correlation with lymph node metastasis and patients who didn't meet curative resection especially with lymphovascular invasion or positive margin with submucosal invasion should receive additional gastrectomy [30]. Positive lateral margin was related closely to a mixed-type carcinoma, larger than $3 \mathrm{~cm}$ in size and the upper one third of stomach, reported by Fu et al. [31]. However, there is no research about the risk factor of vertical and lateral incomplete resection in EGCC patients which needs to study in depth.

In the AI and EI group, the five-year overall and disease-specific survival rates were no statistic differences with $96.1-98.3 \%$ and $99.6-100 \%$. No case in the AI and EI group was found lymph node metastasis until now. Only one AI patient died because of a positive lateral margin. We notified the patient that there was a problem with the pathological result and additional surgery was required. However, the patient had some concerns, thinking that he was old, may have a higher risk of surgery, and have a slower recovery. He did not want to perform a second surgery in a short time, so he refused the additional surgery and died 14 months after ESD unfortunately. These findings were consistent with the previous results and the five-year survival rate of ESD surgery was comparable to 
that of radical gastrectomy [32-34]. The five-year overall survival rate of mucosal EGC was $99 \%$ and the fiveyear overall survival rate of submucosal EGC was $96 \%$ by surgical treatment according to the National Cancer Center of Japan [8], which was consistent with the long-term outcome of EGCC patients after ESD at our center. In short, if only the tumor lesions met the absolute or expanded indication, endoscopic resection could achieve satisfactory safety and efficacy from the longterm follow-up. As a consequence, conclusion could be drawn that endoscopic resection was an effective way for the EGCC patients within the AI and EI group similar to other studies $[4,35,36]$.

However, there are still many concerns in terms of the BEI group. In this study, the rate of en bloc resection arrived at 98.9\% (93/94) in BEI group. Yet, The BEI group showed lower rates of complete resection $(74.5 \%, 70 / 94)$ $(P<0.001)$. The reason for the result was mainly related to tumor lesion size, lymphatic/vascular invasion, deep submucosal invasion and undifferentiated histology. These factors were closely related to lymph node metastasis and recurrence [37-39]. As a result, these patients were not suitable for endoscopic resection from the results of previous researches. We evaluated the tumor lesions by EUS, CT or biopsy before ESD and we found some cases were under massive submucosal invasion. Gastrectomy, especially proximal gastrectomy, is the most common surgical treatment of gastric cardiac cancer for the patients unsuitable for ESD. However, some patients suffered from severe postoperative complications, such as anastomotic leakage, reflux esophagitis and anastomotic stricture after proximal gastrectomy. According to the recent reports, the short-term and long-term gastrectomy complications rates could be up to $20 \%$ compared with less than $10 \%$ by ESD [40, 41]. Based on the EGC guideline, BEI group should be recommended additional surgery strongly, however, in our study, only half BEI patients received additional surgery. These patients were aware of beyond the expanded criteria but they still insisted endoscopic resection when they met advanced age, serious underlying diseases and chose the less invasive strategy instead of the surgery. In addition, 2.4\% (1/42) patient dead because of massive hemorrhage after the additional gastrectomy, which was far higher than the mortality rate reported in the literatures. It has been reported that the rate of delayed massive hemorrhage after gastrectomy in patients with gastric cancer was $0.9 \%$ with $0.2 \%$ death rate [42]. Park's study showed the incidence of the postoperative bleeding was $0.8 \%$ and the subsequent mortality rate was $0.08 \%$ [43]. This may be the result of bias due to the low number of cases included in our research. According to our research, the death rate of patients without additional surgery in the BEI group is lower than that of patients with additional surgery, which caught our attention $(2.4 \%$ vs $4.4 \%)$. Due to the small number of cases, there was no significant difference in 5-year survival with or without additional surgery. The content of this part needs further research. Although surgical procedures have certain risks, for these two young BEI patients who died of metastases due to no additional surgery, perhaps additional surgery after ESD may give them the possibility of long-term survival.

We found that the five-year overall survival rate and the disease specific survival rate for the BEI group patients up to $89.1 \%$ and $96.6 \%$ during the long-term follow-up at our center. In other centers, endoscopists found the similar results which the five-year disease-free survival rate of BEI patients after ESD could be as high as $90 \%$ or more, which was quite effective [32, 44, 45]. Yet, the diseasespecific survival of the BEI group was still significantly lower than that of the AI and EI groups, which suggests that we need to carefully consider the next step of treatment for these patients in the BEI group after ESD. After we have fulfilled the obligation of the doctor to inform, the patient should follow the doctor's advice and perform additional surgical operations to prevent the occurrence of tragedies. The rates of $\mathrm{R} 0$ resection and curative resection in BEI group may be lower than the patients in the indications, but in the long run, the survival rate in the BEI group patients who underwent ESD instead of radical gastrectomy still showed a favorable performance. According to a large-scale multi-center study conducted by Takizawa and Hatta et al., the authors found that out of 905 non-curative resection patients without additional surgery, a total of 27 patients had recurrence (27/905, $3.0 \%$ ), of which distant metastasis was the most common way of recurrence $(15 / 27,60 \%)$ [46]. In contrast, in our study, $4.4 \%$ of patients with non-curative resection without additional surgery died of distant metastases. It reminds us that endoscopists would strongly recommend the BEI patients to receive additional surgery after ESD. The necessity for additional surgery needs to be repeatedly emphasized to patients to increase their attention. Besides, between the two groups with or without surgery, we concluded that there was no significant statistical difference from the K-M survival curve. Different from the previous studies $[40,47]$, those patients under BEI group didn't benefit from the additional surgery neither the five-year overall survival nor the five-year diseasespecific survival. Based on the eCura system, it could be a useful aid for selecting the appropriate treatment strategy after the noncurative ESD for EGCC [39]. If we followed up long enough or enrolled more cases, a different conclusion might jump to us.

Our study still has several limitations. First, this research is a single center retrospective cohort 
analysis which may leads to a section bias and referral bias. Besides, an average of 48.1 months of follow-up may not allow us to find the significant difference in the survival rate of the BEI patients with or without additional surgery. In this rather small subgroup, the survival did not show significant differences possibly because of the minor case number. In addition, we are urge to learn about the risk factors of positive margins and noncurative resection.

\section{Conclusion}

Endoscopic resection of EGCC could achieve a favorable short-term and long-term prognosis for patients with absolute and expanded indication. Patients in beyond the expanded indication showed generally favorable clinical outcomes and needed to be carefully checked after ESD. ESD may be an optional treatment for the patients unsuitable for gastrectomy.

\author{
Abbreviations \\ EGC: Early gastric cancer; EGCC: Early gastric cardiac cancer; EGJ: Esophago- \\ gastric junction; ESD: Endoscopic submucosal dissection; EMR: Endoscopic \\ mucosal resection; Al: Absolute indication; El: Expanded indication; $\mathrm{BEI}$ : \\ Beyond the expanded indication.
}

\section{Supplementary Information}

The online version contains supplementary material available at https://doi. org/10.1186/s12876-021-01700-0.

Additional file 1: Figure 1. Flow diagram for the patients in this study. Figure 2. The endoscopic submucosal dissection for early gastric cardiac cancer. Figure 3. Patient treatment flow chart. Table 1. Disease specific survival at 3 and 5 years among BEl patients with or without additional surgery after ESD for EGCC which were divided into three risk categories according to the eCura system.

\section{Acknowledgements}

Thanks to all the people participated in this article and the support of the hospital and department.

\section{Authors' contributions}

$X Z 2$ and $G X$ designed the research; XZ1, YL, LW and TL performed surgeries; $\mathrm{QS}, \mathrm{QH}$ and XF analyzed the pathological section; SC and SZ interpreted the results; TF drafted manuscript. TF, QS, SC, XF, QH, SZ, YL, XZ1, TL, LW, XZ2 and $\mathrm{GX}$ approved final version of manuscript. All authors read and approved the final manuscript.

\section{Funding}

This work was supported by grants from the National Natural Science Foundation of China (Grant Nos. 81572338 and 81672380, 81201909, 81602089), the Nanjing Medical Science and Technology Development Program (Nos. YKK 12072, YKK 15061 and YKK 16078). This work was also supported by the C-class sponsored research project of the Jiangsu Provincial Six talented Peaks (WSN-078). The funding bodies played no role in the design of the study and collection, analysis, and interpretation of data and in writing the manuscript.

\section{Availability of data and materials}

The datasets used during the current study are available from the corresponding author on reasonable request.

\section{Declarations}

\section{Ethics approval and consent to participate}

The study protocol was approved by the Human Ethics Review Committees of Nanjing Drum Tower Hospital. Verbal informed consent was obtained from each patient, and the Ethics Committee approved this procedure. Since this is a retrospective study, a waiver of written informed consent was obtained from the Ethics Committee. The data used in this study was anonymized before its use.

\section{Consent for publication}

All the authors agreed to publish the research article.

\section{Competing interests}

The authors declare that they have no competing interests.

\section{Author details}

${ }^{1}$ Department of Gastroenterology, Nanjing Drum Tower Hospital Clinical College of Nanjing Medical University, Nanjing, China. ${ }^{2}$ Department of Pathology, Nanjing Drum Tower Hospital, The Affiliated Hospital of Nanjing University Medical School, Nanjing, China. ${ }^{3}$ Department of Gastroenterology, Nanjing Drum Tower Hospital, The Affiliated Hospital of Nanjing University Medical School, Nanjing, China. ${ }^{4}$ Department of Pathology and Laboratory Medicine, VA Boston Healthcare System and Harvard Medical School, Boston, USA.

Received: 19 March 2020 Accepted: 1 March 2021

Published online: 12 March 2021

\section{References}

1. Huang Q, Fang C, Shi J, Sun Q, Wu H, Gold JS, et al. Differences in clinicopathology of early gastric carcinoma between proximal and distal location in 438 Chinese patients. Sci Rep. 2015;5:13439.

2. Chen L, Wang YH, Cheng YQ, Du MZ, Shi J, Fan XS, et al. Risk factors of lymph node metastasis in 1620 early gastric carcinoma radical resections in Jiangsu Province in China: a multicenter clinicopathological study. J Dig Dis. 2017;18(10):556-65.

3. Hoteya S, Matsui A, lizuka T, Kikuchi D, Yamada A, Yamashita S, et al. Comparison of the clinicopathological characteristics and results of endoscopic submucosal dissection for esophagogastric junction and non-junctional cancers. Digestion. 2013;87(1):29-33.

4. Tate DJ, Klein A, Sidhu M, Desomer L, Awadie H, Lee EYT, et al. Endoscopic submucosal dissection for suspected early gastric cancer: absolute versus expanded criteria in a large Western cohort (with video). Gastrointest Endosc. 2019:90(3):467-479.e464.

5. Siegel RL, Miller KD, Jemel A. Cancer statistics, 2018. CA Cancer J Clin. 2018;68(1):7-30.

6. Arnold M, Moore SP, Hassler S, Ellison-Loschmann L, Forman D, Bray F. The burden of stomach cancer in indigenous populations: a systematic review and global assessment. Gut. 2014;63(1):64-71.

7. Lang T, Liu Y, Zheng Z, Ran W, Zhai Y, Yin Q, et al. Cocktail strategy based on spatio-temporally controlled nano device improves therapy of breast cancer. Adv Mater (Deerfield Beach, Fla). 2019;31(5):e1806202.

8. Japanese Gastric Cancer Association. Japanese gastric cancer treatment guidelines 2014 (ver.4). Gastric Cancer. 2017;20(1):1-19.

9. Japanese Gastric Cancer Association. Japanese classification of gastric carcinoma: 3rd English edition. Gastric Cancer. 2011;14(2):101-12.

10. Du MZ, Gan WJ, Yu J, Liu W, Zhan SH, Huang S, et al. Risk factors of lymph node metastasis in 734 early gastric carcinoma radical resections in a Chinese population. J Dig Dis. 2018;19(10):586-95.

11. Fang C, Shi J, Sun Q, Gold JS, Xu GF, Liu WJ, et al. Risk factors of lymph node metastasis in early gastric carcinomas diagnosed by WHO criteria in 379 Chinese patients. J Dig Dis. 2016;17(8):526-37.

12. Fang C, Huang Q, Lu L, Shi J, Sun Q, Xu GF, et al. Risk factors of early proximal gastric carcinoma in Chinese diagnosed using WHO criteria. J Dig Dis 2015;16(6):327-36.

13. Huang $Q$, Cheng $Y$, Chen L, Mingzhan D, Wang Y, Xu G, et al. Low risk of lymph node metastasis in 495 early gastric cardiac carcinomas: a multicenter clinicopathologic study of 2101 radical gastrectomies for early gastric carcinoma. Modern Pathol. 2018;31(10):1599-607. 
14. Rice TW, Ishwaran H, Ferguson MK, Blackstone EH, Goldstraw P. Cancer of the esophagus and esophagogastric junction: an eighth edition staging primer. JThorac Oncol. 2017;12(1):36-42.

15. Azumi M, Takeuchi M, Koseki Y, Kumagai M, Kobayashi Y, Takatsuna M, et al. The search, coagulation, and clipping (SCC) method prevents delayed bleeding after gastric endoscopic submucosal dissection. Gastric Cancer. 2019;22(3):567-75.

16. Choi JY, Park YS, Na G, Park SJ, Yoon H, Shin CM, et al. Safety and effectiveness of endoscopic mucosal resection or endoscopic submucosal dissection for gastric neoplasia within 2 days' hospital stay. Medicine. 2019;98(32):e16578.

17. Hatta W, Gotoda T, Oyama T, Kawata N, Takahashi A, Yoshifuku Y, et al. A scoring system to stratify curability after endoscopic submucosal dissection for early gastric cancer: "eCura system." Am J Gastroenterol. 2017;112(6):874-81.

18. Coda S, Oda I, Gotoda T, Yokoi C, Kikuchi T, Ono H. Risk factors for cardiac and pyloric stenosis after endoscopic submucosal dissection, and efficacy of endoscopic balloon dilation treatment. Endoscopy. 2009;41(5):421-6.

19. Ahn JY, Jung HY, Choi KD, Choi JY, Kim MY, Lee JH, et al. Endoscopic and oncologic outcomes after endoscopic resection for early gastric cancer: 1370 cases of absolute and extended indications. Gastrointest Endosc. 2011;74(3):485-93.

20. Toyonaga T, Man-i M, East JE, Nishino E, Ono W, Hirooka T, et al. 1,635 Endoscopic submucosal dissection cases in the esophagus, stomach, and colorectum: complication rates and long-term outcomes. Surg Endosc. 2013;27(3):1000-8.

21. Oda I, Saito D, Tada M, lishi H, Tanabe S, Oyama T, et al. A multicenter retrospective study of endoscopic resection for early gastric cancer. Gastric Cancer. 2006;9(4):262-70.

22. Hahn KY, Park CH, Lee YK, Chung H, Park JC, Shin SK, et al. Comparative study between endoscopic submucosal dissection and surgery in patients with early gastric cancer. Surg Endosc. 2018;32(1):73-86.

23. Pyo JH, Lee H, Min BH, Lee JH, Choi MG, Lee JH, et al. Long-term outcome of endoscopic resection vs surgery for early gastric cancer: a non-inferiority-matched cohort study. Am J Gastroenterol. 2016;111 (2):240-9.

24. Gong EJ, Kim DH, Ahn JY, Jung KW, Lee JH, Choi KD, et al. Comparison of long-term outcomes of endoscopic submucosal dissection and surgery for esophagogastric junction adenocarcinoma. Gastric Cancer. 2017;20(Suppl 1):84-91.

25. Park CH, Kim EH, Kim HY, Roh YH, Lee YC. Clinical outcomes of endoscopic submucosal dissection for early stage esophagogastric junction cancer: a systematic review and meta-analysis. Dig Liver Dis. 2015;47(1):37-44.

26. Osumi H, Fujisaki J, Omae M, Shimizu T, Yoshio T, Ishiyama A, et al. Clinicopathological features of Siewert type II adenocarcinoma: comparison of gastric cardia adenocarcinoma and Barrett's esophageal adenocarcinoma following endoscopic submucosal dissection. Gastric Cancer. 2017;20(4):663-70.

27. Jang YS, Lee BE, Kim GH, Park DY, Jeon HK, Baek DH, et al. Factors associated with outcomes in endoscopic submucosal dissection of gastric cardia tumors: a retrospective observational study. Medicine. 2015;94(31):e1201.

28. Park YH, Kim N. Review of atrophic gastritis and intestinal metaplasia as a premalignant lesion of gastric cancer. J Cancer Prev. 2015;20(1):25-40.

29. Yoon H, Kim N. Diagnosis and management of high risk group for gastric cancer. Gut Liver. 2015;9(1):5-17.

30. Suzuki H, Oda I, Abe S, Sekiguchi M, Nonaka S, Yoshinaga S, et al. Clinical outcomes of early gastric cancer patients after noncurative endoscopic submucosal dissection in a large consecutive patient series. Gastric Cancer. 2017;20(4):679-89.

31. Fu QY, Cui Y, Li XB, Chen P, Chen XY. Relevant risk factors for positive lateral margin after en bloc endoscopic submucosal dissection for early gastric adenocarcinoma. J Dig Dis. 2016;17(4):244-51.

32. Sohn SH, Lee SH, Kim KO, Jang BI, Kim TN. Therapeutic outcomes of endoscopic submucosal dissection for early gastric cancer: single-center study. Eur J Gastroenterol Hepatol. 2017;29(1):61-7.
33. Chung IK, Lee JH, Lee SH, Kim SJ, Cho JY, Cho WY, et al. Therapeutic outcomes in 1000 cases of endoscopic submucosal dissection for early gastric neoplasms: Korean ESD Study Group multicenter study. Gastrointest Endosc. 2009;69(7):1228-35.

34. Isomoto H, Shikuwa S, Yamaguchi N, Fukuda E, Ikeda K, Nishiyama H, et al. Endoscopic submucosal dissection for early gastric cancer: a large-scale feasibility study. Gut. 2009:58(3):331-6.

35. Probst A, Schneider A, Schaller T, Anthuber M, Ebigbo A, Messmann $H$. Endoscopic submucosal dissection for early gastric cancer: are expanded resection criteria safe for Western patients? Endoscopy. 2017:49(9):855-65.

36. Kim SG, Park CM, Lee NR, Kim J, Lyu DH, Park SH, et al. Long-term clinical outcomes of endoscopic submucosal dissection in patients with early gastric cancer: a prospective multicenter cohort study. Gut Liver. 2018;12(4):402-10.

37. Li H, Huo ZB, Kong FT, He QQ, Gao YH, Liang WQ, et al. Predictive factors for lymph node metastasis and defining a subgroup treatable for laparoscopic lymph node dissection after endoscopic submucosal dissection in poorly differentiated early gastric cancer. World J Gastrointest oncol. 2018;10(10):360-6.

38. Abdelfatah MM, Barakat M, Lee H, Kim JJ, Uedo N, Grimm I, et al. The incidence of lymph node metastasis in early gastric cancer according to the expanded criteria in comparison with the absolute criteria of the Japanese Gastric Cancer Association: a systematic review of the literature and meta-analysis. Gastrointest Endosc. 2018;87(2):338-47.

39. Niwa H, Ozawa R, Kurahashi Y, Kumamoto T, Nakanishi Y, Okumura K, et al. The eCura system as a novel indicator for the necessity of salvage surgery after non-curative ESD for gastric cancer: a case-control study. PLoS ONE. 2018;13(10):e0204039.

40. Fukunaga S, Nagami Y, Shiba M, Ominami M, Tanigawa T, Yamagami H, et al. Long-term prognosis of expanded-indication differentiated-type early gastric cancer treated with endoscopic submucosal dissection or surgery using propensity score analysis. Gastrointest Endosc. 2017;85(1):143-52.

41. Ahn SH, Jung DH, Son SY, Lee CM, Park DJ, Kim HH. Laparoscopic doubletract proximal gastrectomy for proximal early gastric cancer. Gastric Cancer. 2014;17(3):562-70.

42. Song W, Yuan Y, Peng J, Chen J, Han F, Cai S, et al. The delayed massive hemorrhage after gastrectomy in patients with gastric cancer: characteristics, management opinions and risk factors. Eur J Surg Oncol. 2014;40(10):1299-306.

43. Park JY, Kim YW, Eom BW, Yoon HM, Lee JH, Ryu KW, et al. Unique patterns and proper management of postgastrectomy bleeding in patients with gastric cancer. Surgery. 2014;155(6):1023-9.

44. Kakushima N, Hagiwara T, Tanaka M, Sawai H, Kawata N, Takizawa K, et al. Endoscopic submucosal dissection for early gastric cancer in cases preoperatively contraindicated for endoscopic treatment. United European Gastroenterol J. 2013;1 (6):453-60.

45. Suzuki H, Oda I, Nonaka S, Yoshinaga S, Saito Y. Is endoscopic submucosal dissection an effective treatment for operable patients with clinical submucosal invasive early gastric cancer? Endoscopy. 2013;45(2):93-7.

46. Takizawa K, Hatta W, Gotoda T, Kawata N, Nakagawa M, Takahashi A, et al. Recurrence patterns and outcomes of salvage surgery in cases of noncurative endoscopic submucosal dissection without additional radical surgery for early gastric cancer. Digestion. 2019;99(1):52-8.

47. Jeon MY, Park JC, Hahn KY, Shin SK, Lee SK, Lee YC. Long-term outcomes after noncurative endoscopic resection of early gastric cancer: the optimal time for additional endoscopic treatment. Gastrointest Endosc. 2018;87(4):1003-1013.e1002.

\section{Publisher's Note}

Springer Nature remains neutral with regard to jurisdictional claims in published maps and institutional affiliations. 